\title{
Compressibility of Natural and Synthetic High Polymers at High Pressures
}

\author{
Charles E. Weir
}

\begin{abstract}
Compression data $\left(-\Delta V / V_{0}\right)$ are reported between 1,000 and 10,000 atmospheres for the following materials: dry cellulose, polyvinylidene chloride (Saran), polyethylene, polymonochlorotrifluoroethylene (Kel-F), polytetrafluoroethylene (Teflon), a polyester (Selectron 5003), and raw rubbers, Hycar OR25, Hycar OR15, Neoprene, and Thiokol ST. All compression curves are smooth except that for polytetrafluoroethylene, which shows a transition at 5,500 atmospheres, resulting in a change in volume $\left(\Delta V / V_{0}\right)$ of approximately 2 percent. Coefficients of the cubic equations, $-\Delta V / V_{0}=a(P-2000)+b(P-2000)^{2}+c(P-2000)^{3}$ fitted to the data are as follows: Cellulose: $a=9.26 \times 10^{-6}, b=-3.25 \times 10^{-10}, c=2.93 \times 10^{-15}$; polyvinylidene chloride (Saran): $a=2.17 \times 10^{-5}, \quad b=-1.90 \times 10^{-9}, \quad c=8.73 \times 10^{-14}$; polyethylene: $a=1.89 \times 10^{-5}, \quad b=-1.45 \times 10^{-9}, \quad c=6.10 \times 10^{-14} ; \quad$ polymonochlorotrifluoroethylene (Kel-F): $a=9.89 \times 10^{-6}, \quad b=-4.74 \times 10^{-10}, c=8.29 \times 10^{-15}$; polyester (Selectron 5003): $a=1.76 \times 10^{-5}, \quad b=-1.23 \times 10^{-9}, c=4.82 \times 10^{-14}$; Hycar OR $25: a=2.26 \times 10^{-5}, b=$ $-2.03 \times 10^{-9}, c=9.09 \times 10^{-14} ;$ Hycar OR $15: a=2.17 \times 10^{-5}, b=-2.03 \times 10^{-9}, c=9.42 \times 10^{-14}$; Neoprene: $a=2.04 \times 10^{-5}, b=-1.75 \times 10^{-9}, c=7.66 \times 10^{-14}$; Thiokol ST: $a=1.92 \times 10^{-5}, b=$ $-1.41 \times 10^{-9}, \quad c=6.07 \times 10^{-14}$. Compressibilities calculated from these equations show fictitious minima circa 10,000 atmospheres, although the equations represent the data satisfactorily to 10,000 atmospheres. The data given compare favorably with those obtained on similar materials by previous workers.
\end{abstract}

\section{Introduction}

In a previous paper [1] ${ }^{1}$ the design, construction, and use of apparatus for measurement of volume change of solids (or liquids) at high pressure was described. The apparatus was applied to a determination of the compression of leather and collagen in the forementioned report. This equipment has been applied subsequently for measurement at room temperature of compression of a number of other materials that fall into the two general categories of high polymeric substances and minerals. The data on compression of minerals is primarily of geological interest and will be reported elsewhere. The results of experiments on high polymers are of particular interest here and constitute the subject of this report.

\section{Experimental Method and Treatment of Data}

The apparatus and experimental procedure have been described in detail previously $[1,2]$, and will not be discussed fully here. Briefly, an experiment consists of forcing a leakproof piston into the bore of a heavy-walled cylinder, which contains the specimen immersed in a suitable pressure-transmitting liquid (Varsol, a mixture of naphthenes boiling between $150^{\circ}$ and $200^{\circ} \mathrm{C}$ ). Combination of the measurements of depth of penetration of the piston and the internal hydrostatic pressure - made at each 1,000 atm - with measurements obtained from a similar experiment in which the specimen is replaced by a steel bar of comparable volume, permits a calculation of the compression of the specimen. Suitable equations for the calculation, as well as values of the constants of the vessel and the Varsol required, have been given previously $[2,1]$.

\footnotetext{
Figures in brackets indicate the literature references at the end of this paper.
}

Measurements were made in the pressure range 1,000 to $10,000 \mathrm{~atm}$. The upper limit of $10,000 \mathrm{~atm}$ was self-imposed as a result of a crack existing in the ram, while the lower limit of 1,000 atm is imposed in this type of experiment by frictional forces between packing washers and the bore of the vessel.

The notation used here conforms to that followed for many years by workers at the Geophysical Laboratory of the Carnegie Institute of Washington. The compression $-\Delta V / V_{0}$ is defined as $-\left(V_{p}-V^{\prime}\right) / V_{0}$, where $V_{p}$ is the volume at pressure $P ; V^{\prime}$ is the volume at the experimental reference pressure of 2,000 atm; and $V_{0}$ is the initial volume at atmospheric pressure. The subscript zero may be taken to refer to zero atmospheres, since in these and most other highpressure measurements, the volume change occurring between 0 and $1 \mathrm{~atm}$ is insignificant. The compression occurring between 1 and 2,000 atm is designated by $-\Delta V^{\prime} / V_{0}$ and is equal to $-\left(V^{\prime}-V_{0}\right) / V_{0}$. This compression which is not measured in these experiments is referred to as the initial compression.

Estimation of the initial compression that occurs between 1 and 2,000 atm was made by successive extrapolations of tentative calculations of compression to $1 \mathrm{~atm}$ rather than by the least squares method previously described [1]. While this extrapolation is not to be construed as more than moderately accurate, it is believed sufficiently accurate for the following reason: The required initial compression enters the calculation in a correction term that is usually small. Errors in assessment of the initial compression of as much as a few tenths of a percent result in negligible variation in the measured values between 1,000 and $10,000 \mathrm{~atm}$. However, if the compression is reckoned from $1 \mathrm{~atm}$, the initial compression $\left(-\Delta V^{\prime} / V_{0}, 1\right.$ to $\left.2,000 \mathrm{~atm}\right)$ must be added to the measured values, and the final results will be subject to at least as much uncertainty as is involved in the initial compression. To eliminate this uncer- 
tainty, all data and calculations are based on the experimental reference pressure of $2,000 \mathrm{~atm}$, at which $-\Delta V / V_{0}$ is taken to be zero. Values at 1,000 atm therefore appear as negative compressions, which as a result of the previously mentioned frictional forces, are less reliable than data at higher pressures.

In the present experiments no serious attempt was made to establish the presence of slow plastic flow under hydrostatic pressure. Most observations made during measurements, however, indicate that if such a process occurs a much longer time than was used here must be employed for its detection. Pressure equilibrium in these measurements appeared to be obtained in 15 to 20 minutes following each pressure change, a period of time ordinarily required for establishment of thermal equilibrium [1]. Observations made during measurements were indicative of an instantaneous response to pressure changes in all specimens except Thiokol rubber. The agreement of data obtained in duplicate measurements made on some specimens also tends to indicate negligible permanent set.

During the course of these experiments the dial gage, which was used to measure the depth of penetration of the piston, was remounted directly on the ram itself. Measurements with all rubber samples were made with this arrangement. All other data were obtained with the dial gage mounted on the top platen of the press.

\section{Materials Studied}

There is a scarcity of data on behavior of all polymeric materials in this pressure range, but the choice of materials to be studied was dictated by the Varsol used as the confining liquid. Only those available materials expected to be resistant to swelling by Varsol were studied. The following materials were investigated:

Cellulose.-A sample of purified cotton was compressed into cylindrical form for test and was dried at $100^{\circ} \mathrm{C}$ in vacuum $(<2 \mathrm{~mm} \mathrm{Hg})$ for 48 hours. This specimen is referred to as dry cellulose, and had a density of $1.521 \mathrm{~g} / \mathrm{cm}^{3}$ at $20^{\circ} \mathrm{C}$, as measured by hydrostatic weighing in Varsol [1].

Polytetrafluoroethylene (Teflon).- One sample of Teflon, denoted sample A, was an opaque, grey rod having a density of $2.236 \mathrm{~g} / \mathrm{cm}^{3}$ at $20^{\circ} \mathrm{C}$. The previous history of this sample is unknown. Sample B was obtained from the E. I. Dupont de Nemours $\&$ Co., and was a rod of mottled greyish color having a density of $2.219 \mathrm{~g} / \mathrm{cm}^{3}$ at $20^{\circ} \mathrm{C}$. The mottled appearance was caused by dispersed dark material in the greyish bulk of the rod.

Polymonochlorotrifluoroethylene (Kel-F).*-A sheet of this material was available for test. The material was transparent with a slight opalescence and had a density of $3.168 \mathrm{~g} / \mathrm{cm}^{3}$ at $20^{\circ} \mathrm{C}$. A bundle of strips of suitable width, cut from the sheet, comprised the test specimen.

Polyethylene.-A molded rod, which served as test specimen, had a density of $0.917 \mathrm{~g} / \mathrm{cm}^{3}$ at $20^{\circ} \mathrm{C}$.

\footnotetext{
*This material is of uncertain origin and history.
}

Polyvinylidenechloride (Saran).-A sheet of this substance was available for study.

The material was very dark in color, and had a density of $1.099 \mathrm{~g} / \mathrm{cm}^{3}$ at $20^{\circ} \mathrm{C}$. A bundle of strips cut from the sheet formed the test specimen.

Polyester.-A molded rod of this material was made of Selectron 5003, and was a brittle rigid product having a slightly yellowish cast. The density was found to be $1.190 \mathrm{~g} / \mathrm{cm}^{3}$ at $20^{\circ} \mathrm{C}$.

All rubbers studied were raw stock containing no fillers or added vulcanizing agents, as follows:

Hycar OR25.-A molded cyclinder of density $0.972 \mathrm{~g} / \mathrm{cm}^{3}$ at $20^{\circ} \mathrm{C}$.

Hycar OR15.-A molded cylinder of density 0.964 $\mathrm{g} / \mathrm{cm}^{3}$ at $20^{\circ} \mathrm{C}$.

Neoprene.-A rough cylinder cut manually from an irregularly shaped piece of raw stock. This sample was probably partially crystalline, and had a density of $1.134 \mathrm{~g} / \mathrm{cm}^{3}$ at $20^{\circ} \mathrm{C}$.

Thiokol ST.-A test specimen formed by stacking disks of rubber cut from an irregularly shaped piece of raw material. The density of the specimen was $1.298 \mathrm{~g} / \mathrm{cm}^{3}$ at $20^{\circ} \mathrm{C}$.

\section{Results and Discussion}

\section{Synthetic Plastics and Cellulose}

The results of measurements made on cellulose, polyethylene, polymonochlorotrifluorethylene, polyvinylidene chloride, and a polyester are given in table 1.

The initial volume (at $1 \mathrm{~atm}), V_{0}$; the volume at the reference pressure $(2,000 \mathrm{~atm}), V^{\prime}$; the compression assumed between 1 and $2,000 \mathrm{~atm},-\Delta V^{\prime} / V_{0}$; and the density, $\rho$, are given at the head of the appropriate sections of the table. In some instances duplicate measurements were made on the same specimens to ascertain the reproducibility. Such duplicates are referred to as run 1 and run 2 , and the average of the values obtained appears as a separate column in these instances. The last column of each section contains calculated values of compression obtained by solving the equation: $-\Delta V / V_{0}=a(P-2000)+b(P-2000)^{2}+c(P-2000)^{3}$, which was fitted to the data by the method of least squares. The appropriate values of the constants of the equation are compiled in tabular form in table 4 .

The large compressions experienced by the synthetic materials are to be noted. The decrease in volume of these materials appears to be approximately inversely related to the density, a relationship that has been pointed out frequently by Bridgman [3]. The synthetic polymers are generally more compressible than the natural polymers cellulose and leather reported previously [1]. The dense Kel-F, however, is less compressible than leather and nearly equally compressible as cellulose.

The synthetic materials were weighed in air before and after test to ascertain the amount of absorption of Varsol. The increase in weight noted for all synthetics of table 1, except for polyvinylidene chloride, amounted to no more than $5 \mathrm{mg}$. Poly- 
TABLE 1. Compression of natural and synthetic polymers

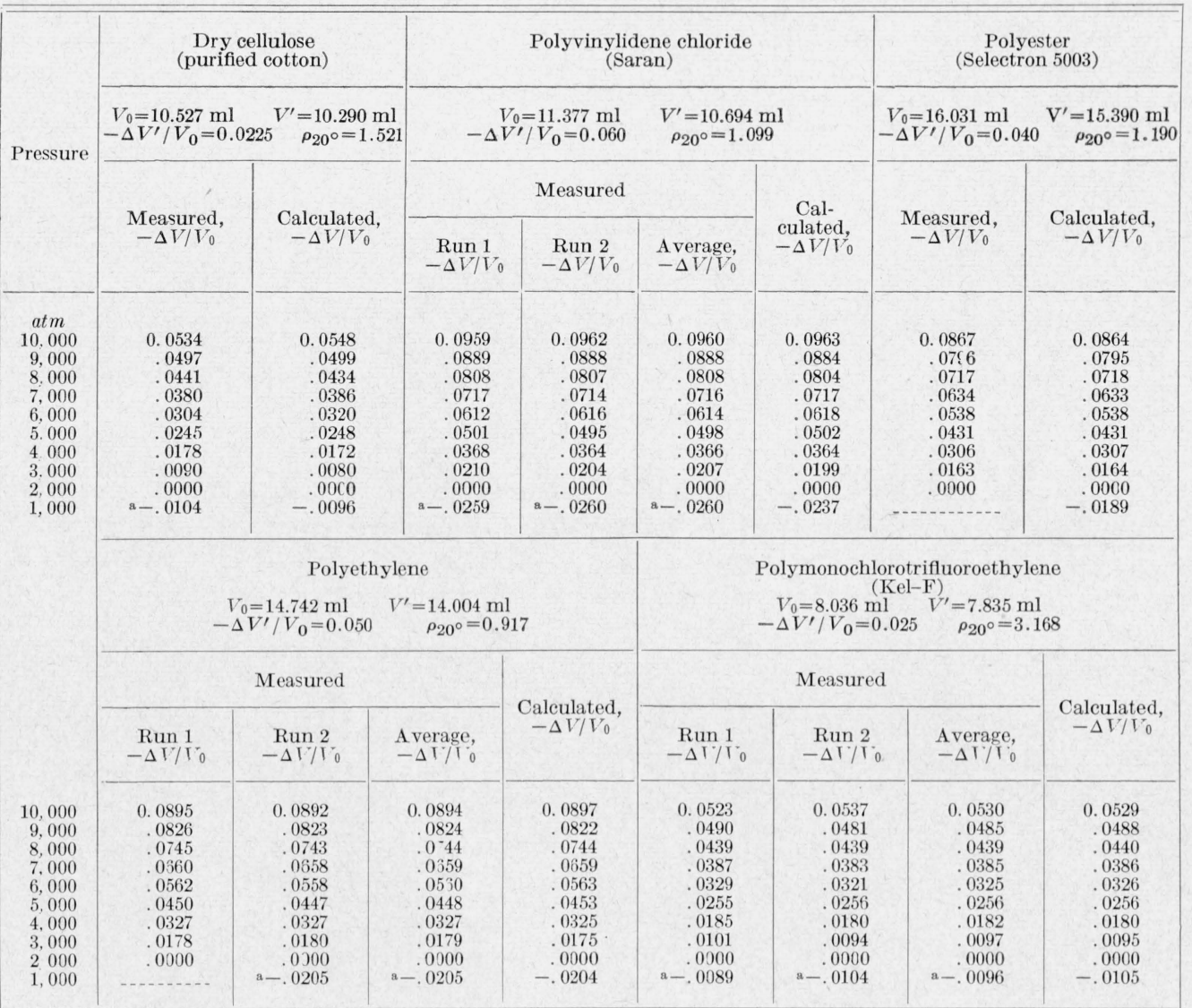

a Values not used in least squares determinations of constants of empirical equations.

vinylidene chloride, however, was observed to be covered with minute blisters after test. This specimen absorbed $0.4 \mathrm{~g}$ of Varsol, corresponding to 3.2 -percent increase in weight during test. While the effect of absorbed Varsol on compressibility is not known, it is probably small, and the data given for polyvinylidene chloride are most probable essentially correct. This absorption of Varsol does create some uncertainty in the present measurements.

The data of table 1 are shown graphically in figure 1 , in which the compression, $-\Delta V / V_{0}$, is plotted against the pressure. The corresponding compressibilities, $\left(-1 / V_{0}\right)(d V / d P)$, obtained by differentiation and solution of the appropriate equations, are plotted as functions of the pressure in figure 2 .

It is noted in figure 2 that while the compressibilities of the synthetic polymers decrease to approximately one-third of their original values at the extreme pressure, the compressibility of cellulose has decreased much less. In particular, the polymonochlorotrifluoroethylene, which exhibits approximately the same compression as cellulose, differs markedly from cellulose in compressibility. It will be noted that a minimum compressibility is indicated in figure 2 at approximately $10,000 \mathrm{~atm}$. This minimum is fictitious, being due to the cubic equation that was used to represent the data.

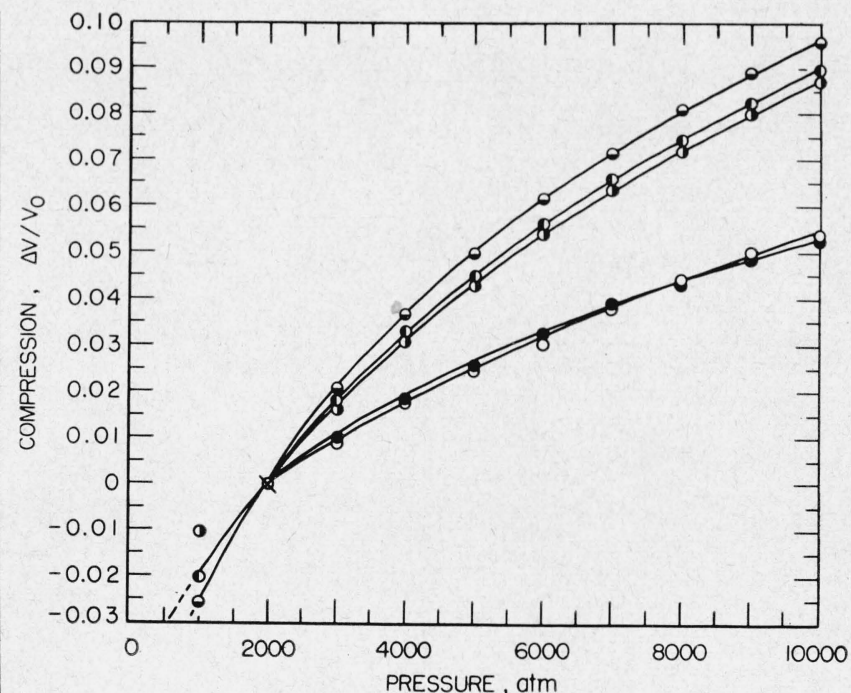

Figure 1. Compression of synthetic plastics and cellulose.

$\Theta$, Polyvinylidene chloride (Saran); 1 , polyester (Selectron 5003); D, polyethylene; , polymonochlorotrifluoroethylene (Kel-F); $\mathrm{O}$, cellulose.

Parks and Richards [4] and Bridgman [5] have reported compression data on polyethylene. Parks and Richards studies were confined to pressures below 2,000 atm. The data presented here are in sub- 


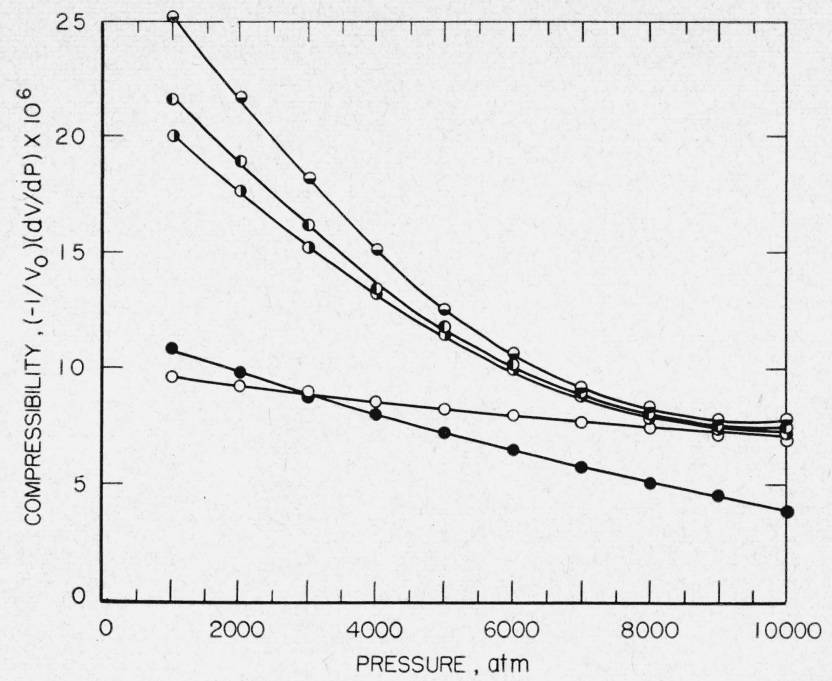

FIgURE 2. Compressibilities of synthetic plastics and cellulose. $\ominus$, Polyvinylidene chloride (Saran); $\mathbf{O}$, polyester (Selectron 5003); $\mathbf{O}$, polyethylene; polymonochlorotrifluoroethylene (Kel-F); O, cellulose.

stantial agreement with their results at 1,000 and $2,000 \mathrm{~atm}$, as far as can be ascertained, since their data are given graphically. However, the compressibility of $5.5 \times 10^{-5} / \mathrm{atm}$ at $1 \mathrm{~atm}$ reported by them is not obtained by extrapolation of the cubic equation fitted to these data. Bridgman [5] reported data on the compressibilities of three samples of polyethylene of differing molecular weights to a maximum pressure of $40,000 \mathrm{~kg} / \mathrm{cm}^{2}$. The present data are in fair agreement with his data at corresponding pressures but in general appear to show slightly higher compressions. The differences are of the general order of a few tenths of a percent in compression.

\section{Polytetrafluoroethylene}

Measurements made on polytetrafluoroethylene (Teflon) differed from all others in that a transition was observed at 5,500 atm. The transition was anticipated in view of previous studies at atmospheric pressure [6], and it was subsequently found that Bridgman [5] had reported this transition under pressure. As the present data differ somewhat from those of Bridgman, it is believed they may be of interest.

Original measurements were made in duplicate on a specimen of uncertain origin-sample A. Observations clearly showed a transition at 5,500 atm, but the volume of the specimen was too small to permit accurate evaluation of the volume change at the transition. The difference in volume between this specimen and the reference steel bar generally used was so large that the data were undesirably sensitive to small variations in the assumed initial compression. A larger specimen of material sample B was procured from the manufacturer and tested. Within experimental error of a few atmospheres, the transition was found at the same pressure in these two specimens. No effort was made to do more than locate the transition with sample $\mathrm{A}$, all serious measurements at this point being conducted with
TABLE 2.-Compression of polytetrafluoroethylene at $25.5^{\circ} \mathrm{C}$ (Teflon)

\begin{tabular}{|c|c|c|c|c|c|c|}
\hline \multirow{2}{*}{ Pressure } & \multicolumn{3}{|c|}{$\begin{array}{c}\text { Sample A } \\
V_{0}=6.565 \mathrm{ml} V^{\prime}=6.368 \mathrm{ml} \\
-\Delta V^{\prime} / V_{0}=0.030 \\
\rho_{20}{ }^{\circ}=2.236\end{array}$} & \multirow{2}{*}{$\begin{array}{c}\text { Sample B } \\
V_{0}=21.241 \mathrm{ml} \\
V^{\prime}=20.604 \mathrm{ml} \\
-\Delta V^{\prime} / V_{0}= \\
0.030 \\
\rho_{20}{ }^{\circ}=2.219 \\
-\Delta V / V_{0}\end{array}$} & \multicolumn{2}{|c|}{$\begin{array}{c}\text { Transition region, } \\
\text { sample } \mathrm{B}\end{array}$} \\
\hline & $\begin{array}{l}\operatorname{Run} 1 \\
-\Delta V / V_{0}\end{array}$ & $\underset{-\Delta V / V_{0}}{\operatorname{Run} 2}$ & $\begin{array}{l}\text { A verage, } \\
-\Delta V / V_{0}\end{array}$ & & $\begin{array}{l}\text { Pres- } \\
\text { sure }\end{array}$ & $-\Delta V / V_{0}$ \\
\hline$a t m$ & & & & & atm & \\
\hline 10,000 & 0.0987 & 0.0987 & 0.0987 & 0.0998 & 5,753 & 0.0672 \\
\hline 9,000 & .0932 & .0945 & .0938 & .0930 & 5,590 & .0616 \\
\hline 8,000 & .0861 & .0864 & .0862 & .0858 & 5,493 & .0557 \\
\hline 7,000 & .0783 & .0799 & .0791 & .0784 & 5,452 & .0524 \\
\hline 6,000 & a. 0696 & a. 0700 & a. 0698 & a. 0694 & 5,390 & 0469 \\
\hline 5,000 & .0359 & .0349 & .0354 & .0389 & 5,280 & .0425 \\
\hline 4,000 & .0251 & .0254 & .0252 & .0267 & . & -..... \\
\hline 3,000 & .0138 & .0136 & .0137 & .0149 & - & - \\
\hline 2,000 & .0000 & .0000 & .0000 & .0000 & & ..... \\
\hline 1,000 & -.0166 & -.0215 & -.0190 & -.0192 & & - \\
\hline
\end{tabular}

a $-\Delta V / V_{0}$ resulting from transition 0.0235

sample B, which was of such volume that variations in assumed initial compression produced only small differences in compression. As the temperature was not controlled, all data refer to the average ambient temperature of $25.5^{\circ} \mathrm{C}$. The results obtained on these measurements are shown in table 2 .

The original volumes, measured densities, volumes assumed at 2,000 atm, and the initial compressions used are given at the head of each section of the table. Measurements made in the transition region are given at the right of the table. The data are shown graphically in figure 3.

The transition is observed as the large compression caused by a small pressure change in the range about 5,500 atm. The transition occurs over a definite pressure range, and is not, therefore, considered to take place at a fixed pressure. The change of volume at transition is estimated to be 2.35 percent of the original volume, a value in substantial agreement with the 2.26 percent reported by Bridgman [5]. The transition, however, is reported by Bridgman to occur at $6,500 \mathrm{~kg} / \mathrm{cm}^{2}(\approx 6,300 \mathrm{~atm})$ as compared to the 5,500 atm observed here. Rela-

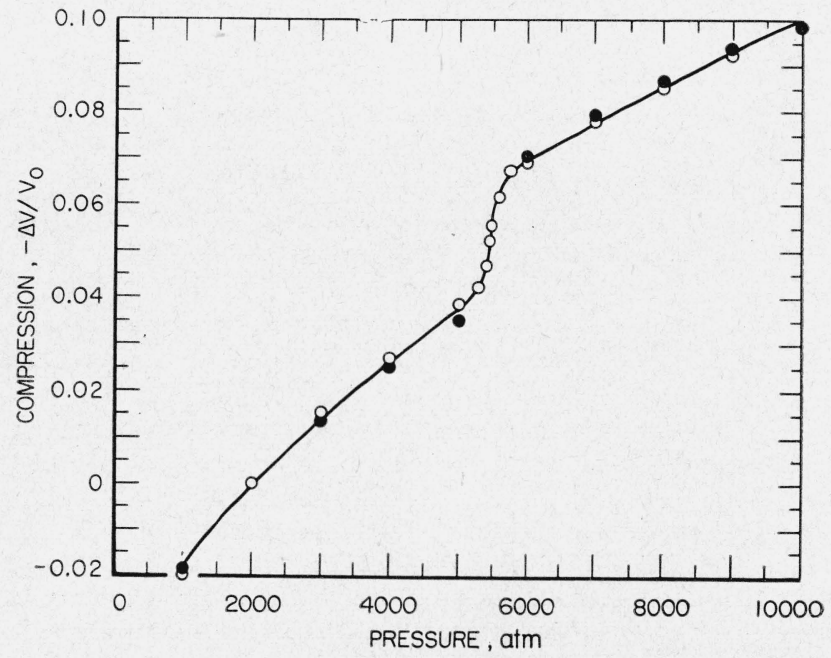

Frgure 3. Compression of polytetrafluoroethylene.

Sample A; O sample B. 
tive volume changes at beginning and end of transition are also at variance with Bridgman's values, but this discrepancy is due almost entirely to the difference in the initial compression of 0.0300 used here as compared with the 0.0527 used by Bridgman. Substantially larger compressions reported here are not due to this factor, at least in sample B in which a change of 0.0200 of the initial compression changes the compression calculated at 10,000 atm by only 0.2 percent. The differences between these data and those of Bridgman [5] may arise from differences in samples or in temperature of measurement, but no other explanations can be offered.

Suitable equations to represent the compression of this material were not obtained, as too few points were obtained above or below the transition to permit accurate curve fitting. However, comparisons of curves and data permit the conclusion that this material is slightly less compressible than polyethylene above the transition, and considerably less compressible below the transition pressure. It is much more compressible than polymonochlorotrifluoroethylene however, over the whole range studied. The divergence of the behavior of these three materials is marked, particularly, as no analogous transition occurs for polyethylene or polymonochlorotrifluoroethylene in this pressure range or even up to $40,000 \mathrm{~kg} / \mathrm{cm}^{2}$ for polyethylene [5].

\section{Raw Rubbers}

Compression data on raw rubbers are given in table 3. The pertinent volume and density figures are given at the head of each section, while the corresponding constants of the cubic equations fitted to the data are compiled in table 4.

These results show that the compression of the rubbers is of the same general numerical order of magnitude as that of the synthetic polymers that are not elastomers (table 1). Despite the wide variety of chemical compositions involved in the samples, there is relatively little change in compression. It seems, therefore, that the compression of these types of materials is governed largely by the gross nature of the chainlike structure, and is influenced to a lesser degree by details of the molecular strueture.

Weights of specimens taken before and after test showed the following pickup of Varsol: Thiokol ST, 0.31 percent; Hycar OR15, 0.11 percent; Hycar OR25, 0.09 percent; Neoprene, 4.8 percent. As a portion of the increase in weight at least is very probably due to Varsol held in void spaces, it is believed that, except for Neoprene, the compression data given are not subject to uncertainty arising from absorption of varsol. The Neoprene specimen, which was obviously porous, absorbed Varsol with visible surface swelling, and the effect of this absorption on the compression is not known.

A difference in behavior between Thiokol ST and the other rubbers was noted during the measurements. The Thiokol rubber appeared to react sluggishly to pressure changes in contrast to the instantaneous response exhibited by the other
TABLE 3. Compression of raw rubbers

\begin{tabular}{|c|c|c|c|c|}
\hline \multirow{3}{*}{ Pressure } & \multicolumn{2}{|c|}{ Нусаг OR-25 } & \multicolumn{2}{|c|}{ Hycar OR-15 } \\
\hline & $\begin{array}{l}V_{o}=21.074 \mathrm{ml} \\
-\Delta V^{\prime} / V_{u}=0.060\end{array}$ & $\begin{array}{c}V^{\prime}=19.810 \mathrm{ml} \\
\rho_{20}=0.972\end{array}$ & $\begin{array}{l}V_{o}=19.343 \mathrm{ml} \\
-\Delta V^{\prime} / V_{o}=0.060\end{array}$ & $\begin{array}{l}V^{\prime}=18.182 \mathrm{ml} \\
\rho_{20}=0.964\end{array}$ \\
\hline & $\begin{array}{l}\text { Measured, } \\
-\Delta V / V_{o}\end{array}$ & $\begin{array}{l}\text { Calculated, } \\
-\Delta V / V_{o}\end{array}$ & $\begin{array}{l}\text { Measured, } \\
-\Delta V / V_{0}\end{array}$ & $\begin{array}{l}\text { Calculated, } \\
-\Delta V / V_{o}\end{array}$ \\
\hline \multirow[t]{4}{*}{$\begin{array}{c}\text { atm } \\
10,000 \\
9,000 \\
8,000 \\
7,000 \\
6,000 \\
5,000 \\
4,000 \\
3,000 \\
2,000 \\
1,000\end{array}$} & $\begin{array}{r}0.0969 \\
.0898 \\
.0818 \\
.0732 \\
.0632 \\
.0516 \\
.0375 \\
.0203 \\
.0000 \\
\mathrm{a}-.0265\end{array}$ & $\begin{array}{r}0.0969 \\
.0895 \\
.0818 \\
.0734 \\
.0636 \\
.0518 \\
.0377 \\
.0206 \\
.0000 \\
-.0246\end{array}$ & $\begin{array}{r}0.0922 \\
.0858 \\
.0781 \\
.0696 \\
.0602 \\
.0495 \\
.0363 \\
.0203 \\
.0000 \\
-.0265\end{array}$ & $\begin{array}{r}0.0925 \\
.0853 \\
.0779 \\
.0698 \\
.0606 \\
.0495 \\
.0361 \\
.0198 \\
.0000 \\
-.0237\end{array}$ \\
\hline & \multicolumn{2}{|c|}{ Neoprene } & \multicolumn{2}{|c|}{ Thiokol ST } \\
\hline & \multicolumn{2}{|c|}{$\begin{array}{cc}V_{o}=17.711 \mathrm{ml} & V^{\prime}=16.781 \mathrm{ml} \\
-\Delta V^{\prime} / V_{0}=0.0525 & \rho_{20}=1.134\end{array}$} & \multicolumn{2}{|c|}{$\begin{array}{cc}V_{o}=19.786 \mathrm{ml} & V^{\prime}=18.797 \mathrm{ml} \\
-\Delta \bar{V}^{\prime} / V_{o}=0.050 & \rho_{2 n} \circ=1.298\end{array}$} \\
\hline & $\begin{array}{l}\text { Measured, } \\
-\Delta V / V_{o}\end{array}$ & $\begin{array}{l}\text { Calculated, } \\
-\Delta V / V_{0}\end{array}$ & $\begin{array}{l}\text { Measured, } \\
-\Delta V / V_{0}\end{array}$ & $\begin{array}{l}\text { Calculated, } \\
-\Delta V / V_{0}\end{array}$ \\
\hline $\begin{array}{r}10,000 \\
9,000 \\
8,000 \\
7,000 \\
6,000 \\
5,000 \\
4,000 \\
3,000 \\
2,000 \\
1,000\end{array}$ & $\begin{array}{r}0.0908 \\
.0839 \\
.0763 \\
.0680 \\
.0587 \\
.0476 \\
.0347 \\
.0187 \\
.0000 \\
\mathrm{a}-.0245\end{array}$ & $\begin{array}{r}0.0909 \\
.0837 \\
.0763 \\
.0681 \\
.0587 \\
.0477 \\
.0345 \\
.0188 \\
.0000 \\
-.0221\end{array}$ & $\begin{array}{r}0.0940 \\
.0859 \\
.0775 \\
.0683 \\
.0577 \\
.0464 \\
.0331 \\
.0180 \\
.0000 \\
\mathrm{~s}-.0227\end{array}$ & $\begin{array}{r}0.0941 \\
.0858 \\
.0773 \\
.0682 \\
.0580 \\
.0465 \\
.0332 \\
.0178 \\
.0000 \\
-.0205\end{array}$ \\
\hline
\end{tabular}

a Values not used in least squares determinations of constants of empirical equations.

rubbers. No explanation can be given for this behavior.

The data of table 3 are shown graphically in figure 4, and the corresponding compressibilities calculated from the equations given in table 4 are shown in figure 5.

The compressibilities shown in figure 5 decrease rapidly with pressure, and appear to level off at about $10,000 \mathrm{~atm}$. This apparent minimum is the

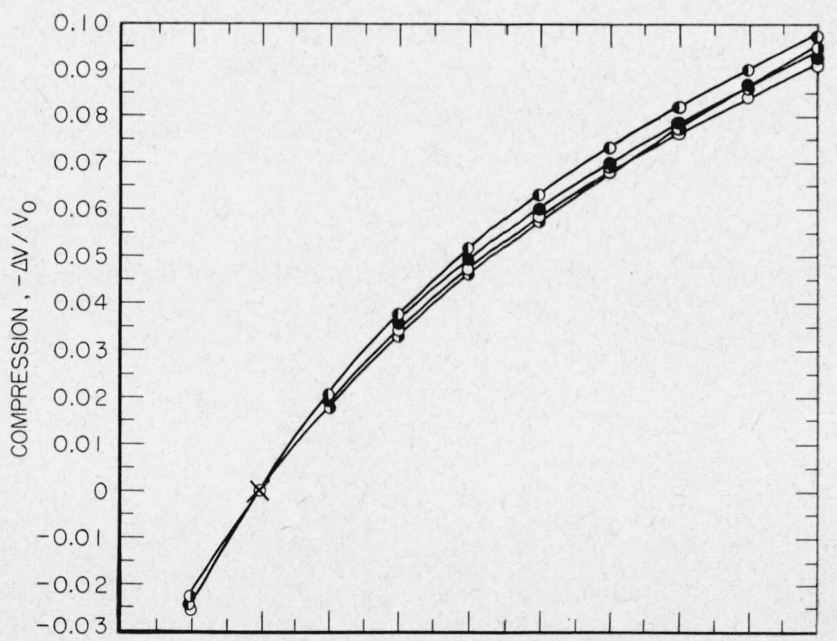

Figure 4. Compression of raw rubbers.

- Hycar OR25; D. Hycar OR15; O, Neoprene; O, Thiokol ST. 
direct result of the equations used for calculation, all of which exhibit a minimum in the first derivative at about 10,000 atm. A pronounced similarity - exists between the compressibility curves of figure 5 and most of those of figure 2.

Compressibility data on rubber have been reported by a few other workers, all of whom, as far as can be ascertained, studied rubbers that were vulcanized. Copeland [7] presented data that cannot be conveniently compared with the present results. The data of Scott [8], obtained on rubbers with varying sulfur contents, terminate at a maximum pressure of 800 bars. Extrapolation of his data at $25^{\circ} \mathrm{C}$ on rubber of 3-percent sulfur content yields a compressibility of approximately $26 \times 10^{-6} / \mathrm{atm}$ at $1,000 \mathrm{~atm}$, which is numerically comparable with the values shown in figure 5. The present data, however, on extrapolation will not give the high compressibilities shown by Scott at pressures below 800 bars. Bridgman [3] reported the compressions of a number of vulcanized rubbers, some of which contained filler at a few pressures up to $25,000 \mathrm{~kg} / \mathrm{cm}^{2}$, but the present values are slightly higher at corresponding pressures. Bridgman also reported a discontinuity in the pressure-compression $\left(-\Delta V / V_{0}\right)$ curves of some samples that most probably corresponds to the second-order transition [9]. This discontinuity is not shown by Adams and Gibson [10] who worked with similar rubbers, or by the present data on raw rubbers. The present data agree well at low pressures with the results obtained by Adams and Gibson on a rubber sample containing 4 percent of sulfur. At higher pressures the present values are slightly lower, a difference probably due to differences in rubbers studied. The cubic equations obtained by these authors are very similar to the present equations. Adams and Gibson noted the minimum compressibility at 10,000 atm previously mentioned as arising from the cubic equation used to represent the data.

The absence of the discontinuity reported by Bridgman [3] in this study, and that of Adams and Gibson [10] is puzzling, and no explanation can be offered. It is important to note, however, that the maximum decrease in volume on compression

TABLE 4. Constants of empirical equation a $-\Delta V / V_{0}=a(P-20000)+b(P-20000)^{2}+c(P-20000)^{3}$

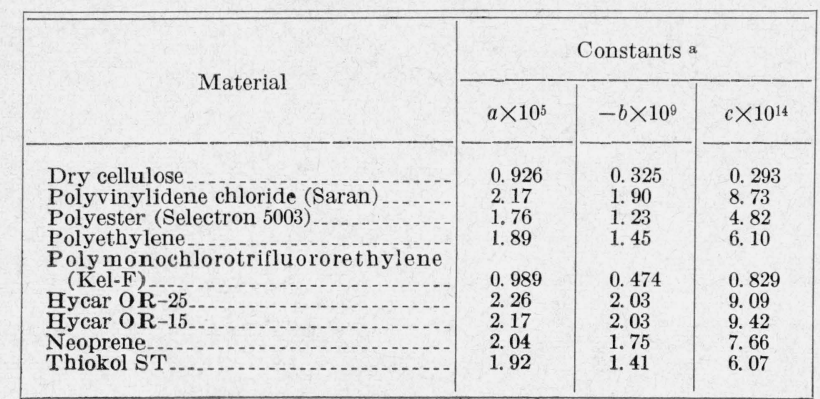

2 Constants given are applicable at room temperature $\left(20^{\circ} \mathrm{C}\right.$ to $\left.25^{\circ} \mathrm{C}\right)$ over the pressure range 2,000 to $10,000 \mathrm{~atm}$.

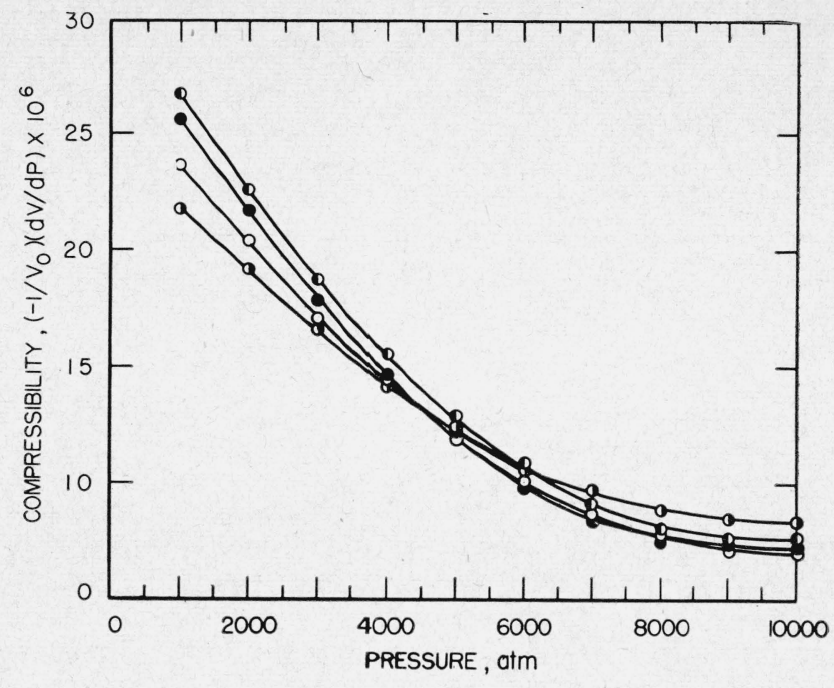

FIguRE 5. Compressibilities of raw rubbers.

- Hycar OR25; D, Hycar OR15; O, Neoprene; Thiokol ST.

of approximately 15 percent is far in excess of the decrease in volume of approximately 6 percent, which occurs between room temperature and $-65^{\circ} \mathrm{C}$ - the second-order transition temperature of naturaI rubber-as a result of thermal contraction. As the transition temperatures of most of the rubbers subjected to pressure here are above $-65^{\circ} \mathrm{C}[9,11]$, the discrepancy is even greater and indicates that the second-order transition is not a result of change in volume alone.

The measurements reported here were made by the author in the laboratories of the Geophysical Laboratory of the Carnegie Institution of Washington. The author is indebted to workers of the Geophysical Laboratory for their suggestions and encouragement, as well as the use of their facilities, without which these measurements could not have been completed.

\section{References}

[1] C. E. Weir, J. Research NBS 45, 465 (1950) RP2160.

[2] L. H. Adams, E. D. Williamson, and J. Johnston, J. Am. Chem. Soc. 411, 12 (1919).

[3] P. W. Bridgman, Proc. Am. Acad. Arts Sci. 76, 9 (1945).

[4] W. Parks and R. B. Richards, Trans. Faraday Soc. 45, 203 (1949).

[5] P. W. Bridgman, Proz. Am. Acad. Arts Sci. z6, 71 (1948).

[6] H. A. Rigby, C. Bunn, Nature 164, 583 (1949); R. N. Work, National Bureau of Standards, unpublished.

[7] L. E. Copeland, J. Applied Phys. 19, 434 (1948).

[8] A. H. Scott, J. Research NBS 14, 99 (1935) RP760.

[9] R. F. Boyer and R. S. Spencer, Advances in colloid science II, chapter I, H. Mark and G. S. Whitby (Interscience Publishers Inc., New York, N.Y., 1946).

[10] L. H. Adams and R. E. Gibson, J. Wash. Acad. Sci. 20, 213 (1930).

[11] R. N. Work, National Bureau of Standards, unpublished.

Washington, September 26, 1950. 